\title{
Farelo de coco na ração de poedeiras comerciais: digestibilidade dos nutrientes, desempenho e qualidade dos ovos
}

\author{
Raffaella Castro Lima ${ }^{1}$, Maria de Fátima Freire Fuentes ${ }^{2}$, Ednardo Rodrigues Freitas ${ }^{2}$, \\ Francislene Silveira Sucupira ${ }^{3}$, Rafaele Ferreira Moreira ${ }^{3}$, Nádia de Melo Braz ${ }^{1}$ \\ ${ }^{1}$ Curso de graduação em Zootecnia, Universidade Federal do Ceará (UFC), Caixa Postal 12167, CEP: 60021-970, Fortaleza - CE. Bolsista \\ PIBIC/CNPq. \\ 2 Departamento de Zootecnia, UFC, Caixa Postal 12167, 60021-970, Fortaleza - CE. \\ 3 Programa de Pós-graduação em Zootecnia, Departamento de Zootecnia, UFC.
}

\begin{abstract}
RESUMO - Um experimento foi realizado com o objetivo de avaliar o efeito da inclusão de farelo de coco (FC) sobre a digestibilidade dos nutrientes da ração, o desempenho e as características dos ovos de poedeiras comerciais. Cento e cinqüenta poedeiras com 76 semanas de idade foram pesadas e distribuídas em um delineamento inteiramente casualizado, com cinco tratamentos, cada um com cinco repetições de seis aves por unidade experimental. Foram avaliadas cinco rações, uma testemunha, sem FC, e as demais com 5, 10, 15 e 20\% de farelo de coco. As rações foram calculadas para serem isoprotéicas e isocalóricas. A inclusão do FC nas rações aumentou a quantidade de EE, FB e EB da ração. Os níveis de inclusão de FC tiveram efeito quadrático sobre os coeficientes de digestibilidade de MS, N e EB e nos valores de energia metabolizável aparente (EMA) e aparente corrigida para N (EMAn), que atingiram o máximo no nível de $15 \%$ de inclusão. As rações contendo 10 , 15 e 20\% de farelo de coco apresentaram valores de EMA e EMAn superiores aos obtidos com a ração sem FC. Os níveis de FC utilizados não afetaram a porcentagem de postura, o peso do ovo e a massa de ovo. O consumo de ração diminuiu e a conversão alimentar melhorou com a inclusão de 15 e $20 \%$ de FC. Considerando os resultados de digestibilidade da energia das rações, recomenda-se que a inclusão de farelo de coco em rações para poedeiras não deve ultrapassar o nível de 15\%.
\end{abstract}

Palavras-chave: alimento alternativo, característica dos ovos, coeficientes de digestibilidade, consumo de ração

\section{Coconut meal in laying hens diets: nutrients digestibility, performance and egg quality}

\begin{abstract}
This experiment was conducted to evaluate the effect of inclusion of coconut meal (CM) in diets on nutrients digestibility, performance and egg characteristics of commercial laying hens. A total of 150 laying hens, with 76 weeks of age was weighed and allotted to a completely randomized design with five treatments and five replicates of six birds in each experimental unit. Five diets were evaluated, one control, without CM and the others with 5, 10, 15, and 20\% of CM. Diets were formulated to be isoprotein and isonitrogenous. Amounts of EE, CF and GE increased with inclusion of CM in diets. A quadratic effect was observed for the inclusion levels of CM on digestibility coefficients for DM, N, GE and the values of apparent metabolizable energy (AME) and $\mathrm{N}$ corrected apparent metabolizable energy (AMEn) that reached the maximum at $15 \%$ of inclusion. Values of AME and AMEn were higher in diets containing 10, 15, and 20\% of CM than that for diet without CM. Egg production, egg weight and egg mass were not affected by the inclusion levels of CM. Feed intake decreased and feed conversion improved as CM level increased in diets. Considering the results of dietary digestible energy, it could be recommended that coconut meal inclusion in the laying hen diet should not exceed the level of $15 \%$.
\end{abstract}

Key Words: alternative feed, egg characteristics, feed intake, metabolizable coefficients

\section{Introdução}

Na Região Nordeste, entre os alimentos alternativos, destaca-se o farelo de coco (FC), subproduto obtido na industrialização do coco. Avicultores regionais já utilizam esse alimento em pequena escala e, geralmente, sem o conhecimento de seu valor nutricional. Segundo Vasconcelos et al. (1995), para o bom uso desse subproduto, é necessário estabelecer seu nível adequado de inclusão em rações para aves.

Segundo Rostagno et al. (2000), esse subproduto contém 22,3\% de PB, $1.921 \mathrm{kcal}$ de EM/kg de EM para aves; 3,8\% de EE e 13,90\% de FB. Entretanto, de acordo com a tabela de composição de alimentos da Embrapa (1991), esse subproduto contém 25,42\% de PB, $2.523 \mathrm{kcal}$ de EM/kg (para aves), 17,08\% de EE e 12,57\% de FB. De acordo com 
Panigrahi (1989), as variações na composição e no valor nutricional do farelo de coco decorrem do processamento utilizado, que influencia principalmente a quantidade de gordura.

A proteína do farelo de coco pode ser considerada de qualidade inferior à da soja, em virtude de sua deficiência em lisina e dos baixos valores de metionina, fenilalalnina e arginina (Soldevila \& Rojas-Daporta, 1976; Mc Donald et al., 1988). Em razão dessas deficiências e do alto teor de fibra, este subproduto é adicionado em pequenas quantidades em rações para animais monogástricos (FAO, 2003).

Estudos têm sido realizados para determinação do efeito da utilização do farelo de coco em rações para poedeiras, entretanto, os resultados têm sido variáveis e não permitem a recomendação do nível mais adequado de inclusão nas rações. Segundo Panigrahi (1989), poedeiras comerciais não apresentaram dificuldades em consumir e utilizar os nutrientes de rações, entretanto, a cor da gema diminuiu linearmente conforme aumentaram os níveis de farelo de coco na ração. Rodriguez-Palenzuela et al. (1998) relataram que, em virtude da quantidade e do tipo de fibra, a inclusão de farelo de coco nas rações reduz o consumo de ração e o desempenho das aves. Braga et al. (2005) constataram redução no consumo de ração, porém, somente no maior nível testado (20\%), o valor obtido foi significativamente menor em comparação ao controle. Esses pesquisadores também verificaram redução linear na pigmentação das gemas com o aumento do nível de farelo de coco na ração e concluíram que o farelo de coco pode ser incluído em níveis de até $15 \%$ desde que utilizada uma fonte de pigmentação.

Panigrahi (1992) afirmou que as variações na composição do farelo de coco influenciam o valor nutricional desse alimento e, conseqüentemente, a quantidade a ser incluída em rações para aves. Assim, esta pesquisa foi realizada com o objetivo de avaliar os efeitos da inclusão de farelo de coco sobre a composição química da ração, a digestibilidade dos nutrientes, o desempenho e a qualidade dos ovos de poedeiras comerciais.

\section{Material e Métodos}

Foram utilizadas 150 poedeiras comerciais da linhagem Hy-Line W36 com 76 semanas de idade e no segundo ciclo de produção. As aves foram pesadas e distribuídas em um delineamento inteiramente casualizado com cinco tratamentos e cinco repetições de seis aves por unidade experimental. As aves foram alojadas em gaiolas de arame galvanizado $(25 \mathrm{~cm}$ de comprimento $\times 40 \mathrm{~cm}$ de profundidade $\times 30 \mathrm{~cm}$ de altura) que dispunham de bebedouro tipo nipple, comedouro tipo calha e coletor de ovos, em densidade de duas aves por gaiola.

Foram testadas cinco rações (Tabela 1), uma controle, sem farelo de coco e outras quatro, com 5, 10, 15 ou $20 \%$ desse subproduto, formuladas para serem isoprotéicas e isocalóricas (Tabela 1). As rações contendo farelo de coco foram suplementadas com $0,025 \%$ de pigmento natural (Sunred-50).

As rações experimentais foram formuladas segundo recomendações nutricionais propostas pelo manual da linhagem Hy-line e de acordo com a composição dos alimentos descrita na Tabela da Embrapa (1991). Para equilibrar os níveis de energia metabolizável, utilizou-se o óleo de soja e a areia lavada como inerte. Também foram utilizados os aminoácidos sintéticos DL-metionina e L-lisina para ajustar os níveis de metionina e lisina e atender às recomendações mínimas desses aminoácidos.

O farelo de coco é o subproduto da extração do óleo por prensagem e foi obtido de uma empresa local (Ducoco Alimentos). De acordo com as análises de composição química e determinação da energia bruta (Silva \& Queiroz, 2002), o farelo de coco apresentava, com base na MS: 25,09\% de PB; 21,66\% de EE; 15,07\% de FB e $5.391 \mathrm{kcal}$ de $\mathrm{EE} / \mathrm{kg}$. A MS determinada foi de $96,17 \%$.

O período experimental foi de 63 dias, divididos em três períodos de 21 dias. Durante o experimento, as aves receberam ração e água à vontade. Os comedouros foram abastecidos duas vezes ao dia (às $8 \mathrm{~h}$ e às $16 \mathrm{~h}$ ), tendo-se o cuidado de evitar desperdício de ração. O programa diário de luz utilizado foi de 17 horas (natural e artificial) e a coleta de ovos foi feita diariamente às $15 \mathrm{~h}$.

As variáveis de desempenho avaliadas foram: porcentagem de postura (\%), consumo de ração (g/ave), peso do ovo (g), massa de ovo (g) e conversão alimentar (g/g). Para avaliar as características dos ovos, uma vez por semana, após pesagem, três ovos de cada parcela foram selecionados para determinação das unidades Haugh e da coloração da gema (Leque colorimétrico da Roche).

A digestibilidade dos nutrientes das rações foi determinada em um ensaio utilizando-se o método de coleta total de excretas, realizado no final do período experimental. As excretas foram coletadas duas vezes ao dia, no início da manhã e no final da tarde, e em seguida acondicionadas em sacos plásticos e congeladas. Para identificar as excretas provenientes das rações em estudo, adicionou-se $1 \%$ de óxido de ferro nas rações no primeiro e no último dia de coleta.

Ao final do período experimental, foram determinadas a quantidade de ração consumida e a quantidade total de excreta produzida. Após o descongelamento à temperatura ambiente, as excretas foram homogeneizadas para retirada de 
Tabela 1 - Composições percentual e nutricional das rações experimentais

Table 1 - Percentagel and nutritional composition of the experimental diets

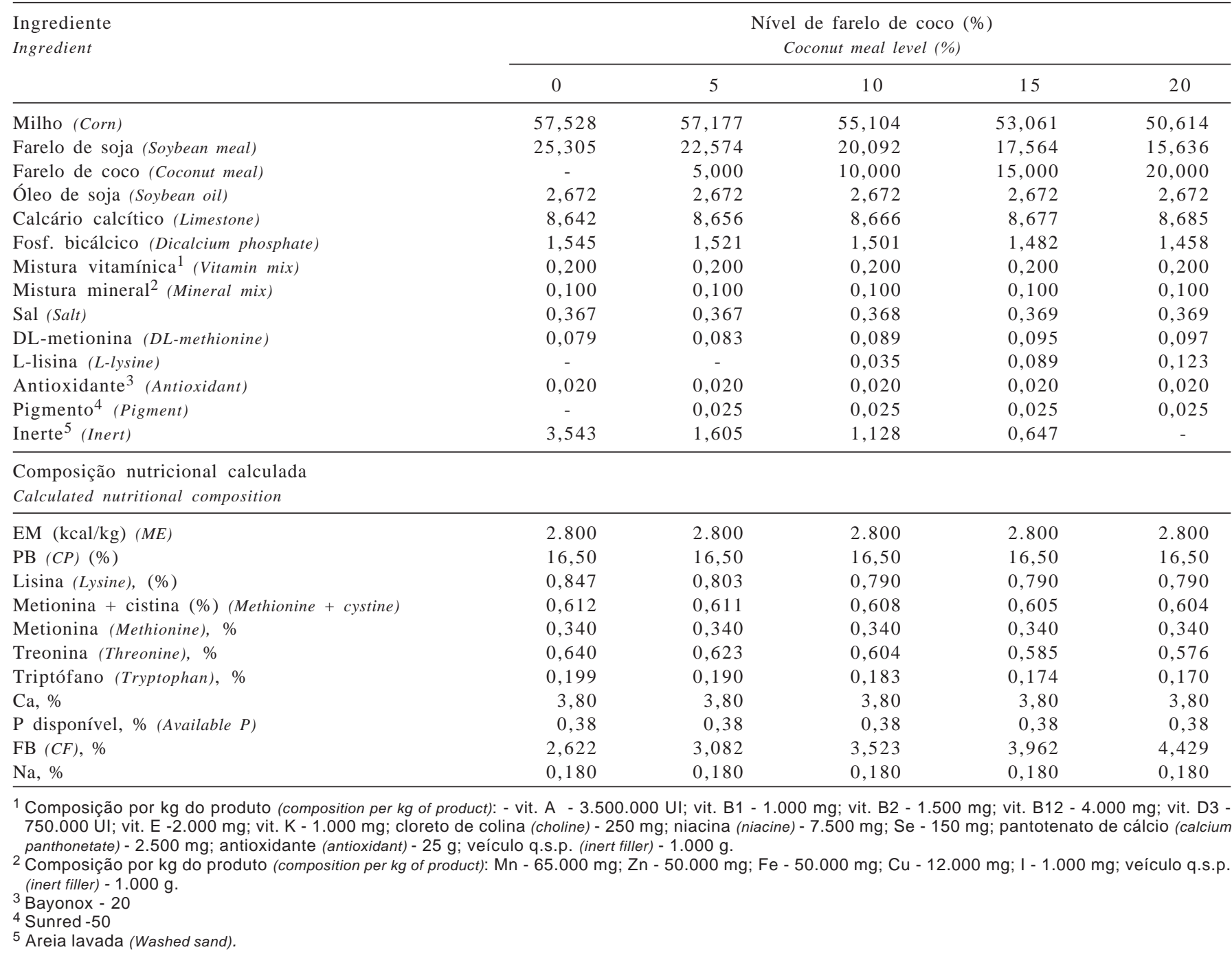

uma amostra, que foi seca em estufa de ventilação forçada a $55^{\circ} \mathrm{C}$ por 72 horas. Em seguida, as amostras foram trituradas em moinho tipo faca e encaminhadas ao laboratório, junto com amostras das rações experimentais, para determinação dos teores de MS, N, EE e FB, segundo metodologia descrita por Silva \& Queiroz (2002). Determinou-se também a energia bruta em bomba calorimétrica adiabática (Modelo 1242, Parr Instruments Co. EUA.).

Com base nos resultados laboratoriais, foram calculados os coeficientes de digestibilidade de MS, EE, N, EB e os valores de energia metabolizável aparente (EMA) e aparente corrigida (EMAn) das rações. A partir dos dados de composição das rações, do consumo de ração pelas aves durante o experimento e dos valores de EMAn determinados, procedeu-se ao cálculo da EMAn (kcal/ave/dia), da PB (g/ave/dia) e da gordura (g/ave/dia) ingeridas.

A análise estatística dos dados foi realizada utilizando-se o SAS (2000) com um modelo inteiramente casualizado. Os graus de liberdade referentes aos níveis de farelo de coco, excluindo-se a ração testemunha (nível zero de inclusão), foram desdobrados em polinômios para o estabelecimento da curva que melhor descrevesse o comportamento dos dados. Os resultados obtidos com cada um dos níveis de farelo de coco foram comparados aos encontrados com a ração controle utilizando-se o teste Dunnet (5\%).

\section{Resultados e Discussão}

A inclusão de farelo de coco promoveu aumento na quantidade de EE, FB e da EB da ração (Tabela 2). Considerando que o óleo de soja foi utilizado para manter as rações isonutrientes e que a mesma proporção foi usada em todas as rações para diminuir os efeitos da adição de gordura, as variações encontradas nas rações podem ser atribuídas à composição do farelo de coco, que é rico em gordura e fibra. 
Tabela 2 - Composição química das rações experimentais Table 2 - Chemical composition of the experimental diets

\begin{tabular}{lrrrrr}
\hline Item & \multicolumn{5}{c}{$\begin{array}{c}\text { Nível de farelo de coco (\%) } \\
\text { Coconut meal level (\%) }\end{array}$} \\
\cline { 2 - 6 } & \multicolumn{1}{c}{0} & \multicolumn{1}{c}{5} & \multicolumn{1}{c}{10} & \multicolumn{1}{c}{15} & \multicolumn{1}{c}{20} \\
\hline MS (\%) (DM) & 91,79 & 91,90 & 91,80 & 91,70 & 92,30 \\
PB $^{1}(\%)(C P)$ & 17,00 & 17,16 & 17,17 & 17,02 & 17,09 \\
EE $^{1}(\%)$ & 7,86 & 9,89 & 13,33 & 14,26 & 15,82 \\
FB $^{1}(\%)(C F)$ & 2,72 & 3,16 & 3,48 & 4,04 & 4,44 \\
EB $^{1}(\mathrm{kcal} / \mathrm{kg})(G E)$ & 3.785 & 3.981 & 4.229 & 4.331 & 4.497 \\
\hline
\end{tabular}

${ }^{1}$ Valores expressos na MS (Values expressed in DM).

A variabilidade da composição química dos alimentos alternativos tem sido uma das principais dificuldades dos nutricionistas, pois a utilização desses alimentos sem análise de composição química, com base apenas nas informações de tabelas de composição de alimentos, implica alterações na composição química e, conseqüentemente, no valor nutricional da ração. Esse fato foi evidenciado nesta pesquisa, quando comparadas a composição calculada (Tabela 1) e a composição determinada (Tabela 2) das rações com os diferentes níveis de farelo de coco. Essa divergência pode ser atribuída ao fato de que, no cálculo das rações, foram utilizados os dados de composição química do farelo de coco descritos na tabela da Embrapa (1991), entretanto, os valores tabelados divergiram da composição química do farelo utilizado, principalmente na quantidade de $\mathrm{EE}$, que era de $20,83 \%$ no farelo de coco utilizado e $17,08 \%$ na tabela da Embrapa (1991).
Rostagno et al. (2000) registraram o valor de 3,80\% de EE e observaram maior diferença em relação ao valor determinado para o farelo de coco utilizado neste experimento. Segundo Panigrahi (1992), o processamento é um dos principais fatores que afetam a composição química do farelo de coco. De acordo com este pesquisador, o farelo obtido da extração do óleo por prensagem (extração mecânica) apresenta maior proporção de gordura em relação ao obtido da extração por solvente, o que pode explicar a grande diferença entre os valores de EE tabelados por Rostagno et al. (2000) e os determinados nesta pesquisa.

De acordo com a análise de regressão, houve efeito quadrático dos níveis de farelo de coco nas rações $(\mathrm{P}<0,05)$ sobre os coeficientes de digestibilidade de MS, N e EB, sobre os valores de EMA e EMAn e efeito linear sobre o coeficiente de digestibilidade do EE (Tabela 3). De acordo com as equações obtidas, a metabolização da MS e da EB aumentou com a inclusão do farelo de coco até aproximadamente 13\%, enquanto, para EMA, EMAn e para o coeficiente de digestibilidade do $\mathrm{N}$, esse aumento ocorreu até o nível de $15 \%$ e reduziu em seguida. A metabolização da gordura sofreu aumento linear conforme aumentaram os níveis de farelo de coco nas rações.

Na comparação das médias pelo teste de Dunnett, observou-se que o coeficiente de digestibilidade do EE da ração com $20 \%$ de farelo de coco foi superior $(\mathrm{P}<0,05)$ ao obtido com a ração controle, enquanto, na ração contendo $5 \%$ de farelo de coco, o coeficiente de digestibilidade do $\mathrm{N}$ foi menor $(\mathrm{P}<0,05)$. Os valores de EMA e EMAn das rações

Tabela 3 - Coeficiente de digestibilidade dos nutrientes e valores de energia metabolizável aparente (EMA) e aparente corrigida para nitrogênio (EMAn) das rações

Table 3 - Coefficients of digestibility of the nutrients and values of apparent metabolizable energy (AME) and apparent metabolizable energy (AMEn) corrected by nitrogen of the diets

\begin{tabular}{|c|c|c|c|c|c|c|}
\hline \multirow[t]{2}{*}{ Item } & \multicolumn{5}{|c|}{$\begin{array}{l}\text { Nível de farelo de coco (\%) } \\
\text { Coconut meal level (\%) }\end{array}$} & \multirow[t]{2}{*}{ CV (\%) } \\
\hline & 0 & 5 & 10 & 15 & 20 & \\
\hline CDMS (\%) (DCDM) ${ }^{1}$ & 69,27 & 68,25 & 71,86 & 71,25 & 69,78 & 3,33 \\
\hline CDN $(\%)(D C N)^{2}$ & 57,59 & $45,99 *$ & 51,67 & 54,28 & 52,42 & 7,32 \\
\hline $\operatorname{CDEE}(\%)(D C E E)^{3}$ & 88,40 & 86,66 & 91,83 & 93,19 & $94,24 *$ & 3,18 \\
\hline CDEB (\%) $(D C G E)^{4}$ & 79,58 & 76,50 & 79,722 & 79,376 & 77,67 & 2,38 \\
\hline EMA $(\mathrm{kcal} / \mathrm{kg} \mathrm{MS})^{5}$ & 3.012 & 3.046 & $3.371 *$ & $3.436^{*}$ & $3.495 *$ & 2,38 \\
\hline$A M E$ & & & & & & \\
\hline $\begin{array}{l}\text { EMAn }(\mathrm{kcal} / \mathrm{kg} \mathrm{MS})^{6} \\
\text { AMEn }\end{array}$ & 2.884 & 2.942 & $3.255^{*}$ & $3.314^{*}$ & $3.378 *$ & 2,26 \\
\hline
\end{tabular}

$1 \hat{\mathrm{Y}}=62,95+1,347 \mathrm{X}-0,051 \mathrm{X}^{2}, \mathrm{R}^{2}=0,27$.

$2 \hat{Y}=36,19+2,322 X-0,075 X^{2}, R^{2}=0,41$.

$3 \hat{Y}=85,45+0,482 X, R^{2}=0,45$.

$4 \hat{Y}=71,37+1,295 X-0,049 X^{2} ; R^{2}=0,33$.

$5 \hat{Y}=2,65+0,095 X-0,003 X^{2}, R^{2}=0,82$.

${ }^{6} \hat{Y}=2,57+0,090 X-0,003 X^{2} ; R^{2}=0,83$.

* Diferente $(P<0,05)$ em relação à ração controle pelo teste Dunnet.

* Differs $(P<0.05)$ from control by Dunnett test. 
com 10, 15 e $20 \%$ de farelo de coco foram superiores $(\mathrm{P}<0,05)$ ao da ração controle.

O aumento na digestibilidade e os valores de EM registrados podem ser atribuídos ao aumento da quantidade de gordura nas rações com a inclusão do farelo de coco (Tabela 2). A presença de gordura na ração pode aumentar a utilização da energia de outros componentes da ração e elevar o tempo de passagem do alimento pelo trato gastrintestinal, promovendo maior digestão e melhor absorção dos nutrientes do alimento (Mateos et al., 1996). Segundo Sakomura et al. (1998, 2004), em aves, com o aumento do teor de gordura na ração, podem ocorrer benefícios relacionados ao efeito extracalórico das gorduras, que consiste no aumento da disponibilidade dos nutrientes de outros ingredientes da ração, e ao efeito extrametabólico das gorduras, que resulta em melhoria da eficiência energética, decorrente do aumento da energia líquida da ração, em razão do menor incremento calórico das gorduras.

Por sua vez, a redução nos coeficientes de digestibilidade da MS e EB, com a inclusão de $13 \%$ ou mais de farelo de coco e na EMA e EMAn e no coeficiente de digestibilidade de $\mathrm{N}$ a partir de $15 \%$, pode ser associada aos efeitos negativos do aumento da quantidade de fibra nas rações. De acordo com Rodríguez-Palenzuela et al. (1998) e Panigrahi (1992), além do alto teor, a fibra do farelo de coco tem alta capacidade relativa de absorção de água. A fração solúvel da fibra produz efeitos negativos no aproveitamento dos nutrientes pelas aves, associados ao aumento da viscosidade intestinal e às alterações morfológicas e fisiológicas no trato digestivo (Classen, 1996).

Segundo Jansen \& Carré (1989), o complexo celulolítico da parede celular dos vegetais, além de ser pouco digerido pelas aves, funciona como uma barreira impedindo a penetração das enzimas e diminuindo a digestão dos nutrientes da ração. Também aumenta a perda endógena de proteína em virtude do aumento da descamação intestinal. Esse efeito da fibra sobre o balanço de nitrogênio reduz o coeficiente de digestibilidade do $\mathrm{N}$.

Os resultados obtidos nesta pesquisa indicam que, para a utilização do farelo de coco na composição das rações, deve-se atentar para a composição e os valores de EM desse subproduto, em virtude das alterações promovidas na digestibilidade dos nutrientes e no valor nutricional dessas rações. Esses resultados corroboram as afirmações de Panigrahi (1992) de que as variações na composição do farelo de coco influenciam o valor nutricional desse alimento e, conseqüentemente, a quantidade a ser incluída na ração de aves.

Na análise de regressão, excluindo-se o nível zero de inclusão, observou-se que o consumo de ração diminuiu linearmente (Tabela 4) com a inclusão de farelo de coco nas rações. Entretanto, apenas nas aves alimentadas com as rações contendo 15 e $20 \%$ de farelo de coco o consumo foi significativamente (Dunnett, 5\%) menor que o das aves alimentadas com a ração sem farelo de coco.

Apesar de o consumo de ração ter variado com a inclusão de farelo de coco, a ingestão de EMAn e de PB pelas aves não foi influenciada $(P>0,05)$; a ingestão de gordura, no entanto, aumentou linearmente (Tabela 4) com a inclusão desse subproduto nas rações. Esse aumento está associado à maior quantidade de gordura nas rações com farelo de coco.

Redução linear no consumo com a inclusão de farelo de coco também foi observada por Braga et al. (2005). Entretanto,

Tabela 4 - Desempenho e características dos ovos de poedeiras comerciais alimentadas com rações contendo diferentes níveis de farelo de coco

Table 4 - Performance and egg characteristics of laying hens fed diets containing different levels of coconut meal

\begin{tabular}{|c|c|c|c|c|c|c|}
\hline \multirow[t]{2}{*}{ Item } & \multicolumn{5}{|c|}{$\begin{array}{l}\text { Nível de farelo de coco (\%) } \\
\text { Coconut meal level }\end{array}$} & \multirow[t]{2}{*}{ CV (\%) } \\
\hline & 0 & 5 & 10 & 15 & 20 & \\
\hline Consumo de ração (g/ave/dia) ${ }^{1}$ (Feed intake, g/bird/day) & 111,64 & 105,92 & 106,46 & $99,15 *$ & $97,54 *$ & 4,89 \\
\hline EMAn ingerida (kcal/ave/dia) (Ingested AMEn, g/bird/day) & 295,50 & 289,30 & 318,20 & 301,60 & 304,00 & 4,96 \\
\hline PB ingerida (g/ave/dia) (Ingested $C P$, g/bird/day) & 50,24 & 49,65 & 54,62 & 51,28 & 51,97 & 5,00 \\
\hline Gordura ingerida (g/ave/dia) (Ingested fat, g/bird/day) & 23,23 & $28,62 *$ & $42,40 *$ & $42,42 *$ & $48,11^{*}$ & 5,88 \\
\hline Porcentagem de postura (ave/dia) (Egg production, bird/day) & 71,83 & 76,77 & 76,59 & 75,32 & 73,36 & 7,43 \\
\hline Peso do ovo (g) (Egg weight, g) & 63,84 & 62,25 & 62,91 & 62,2 & 61,85 & 2,49 \\
\hline Massa de ovo (g/ave/dia) (Egg mass, g/bird) & 45,83 & 47,77 & 48,17 & 46,73 & 45,36 & 6,80 \\
\hline Conversão alimentar (kg/kg) (Feed convertion) & 2,37 & 2,22 & 2,21 & $2,12 *$ & $2,16^{*}$ & 5,05 \\
\hline Coloração da gema ${ }^{2}$ (Egg-yolk colour) & 8,0 & 8,0 & 8,0 & 8,0 & 7,8 & 2,58 \\
\hline Unidades Haugh (Haugh units) & 71,52 & 74,17 & 72,77 & 77,56 & 75,08 & 6,49 \\
\hline
\end{tabular}

* Diferente $(P<0,05)$ em relação à ração controle pelo teste Dunnet.

* Differs $(P<0.05)$ from control by Dunnett test.

$1 \hat{\mathrm{Y}}=110,38-0,65 \mathrm{X} ; \mathrm{R}^{2}=0,36$.

$2 \hat{\mathrm{Y}}=26,06+1,15 \mathrm{X} ; \mathrm{R}^{2}=0,74$. 
Panigrahi (1989) constatou que o consumo de ração por poedeiras não foi influenciado pela adição de 10 e $20 \%$ de farelo de coco. Nesta pesquisa, a redução no consumo pode ser associada à tentativa das poedeiras em regular a ingestão de energia, pois a EMAn das rações aumentou à medida que aumentaram os níveis de farelo de coco na ração (Tabela 3).

A porcentagem de postura não foi influenciada $(\mathrm{P}>0,05)$ pela inclusão do farelo de coco nas rações. Entre os fatores que podem afetar a produção de ovos, destaca-se a ingestão de energia e proteína pelas aves (Pinto et al., 2002; Freitas et al., 2005), todavia, a inclusão de farelo de coco não influenciou a ingestão de energia e proteína pelas aves (Tabela 4), o que justifica os resultados obtidos.

Do mesmo modo, Panigrahi (1989) observou que a produção de ovos em aves alimentadas com rações contendo 10 e $20 \%$ desse farelo não foi significativamente diferente do valor obtido com o fornecimento de ração sem o farelo. Entretanto, Braga et al. (2005) verificaram redução linear na produção de ovos com a inclusão de farelo de coco em níveis superiores a 5\%, embora os resultados não tenham sido significativamente diferentes em relação ao controle, o que confirma em parte as observações desta pesquisa.

O peso do ovo não foi afetado $(\mathrm{P}>0,05)$ pelos níveis de farelo de coco nas rações. Esses resultados estão de acordo com o encontrado por Braga et al. (2005), que notaram que a utilização de farelo de coco nas rações em níveis de até $20 \%$ não afetou o peso dos ovos.

A ingestão de proteína e aminoácidos, principalmente metionina e lisina, é um dos fatores que podem afetar o peso do ovo (Buxadé, 1993). Neste estudo, a ingestão de proteína não diferiu entre os níveis de inclusão de farelo de coco. Por sua vez, a redução na digestibilidade da proteína nos níveis de inclusão superiores a 15\% no ensaio de metabolismo não alterou a disponibilidade de aminoácidos para as aves o suficiente para que houvesse redução no peso dos ovos.

Resultados contrários foram reportados por Mahadevan et al. (1957), que verificaram diminuição no peso do ovo quando o nível de farelo de coco nas rações aumentou para 30 e $40 \%$. Os autores atribuíram esse efeito à deficiência de aminoácidos neste subproduto. Nesta pesquisa, foram utilizados os aminoácidos sintéticos metionina e lisina em quantidade suficiente para atender às exigências mínimas das aves alimentadas com as rações contendo farelo de coco para evitar os possíveis efeitos da deficiência desses aminoácidos nas rações.

A massa de ovo não foi afetada pelos níveis de farelo de coco utilizados nesta pesquisa ( $\mathrm{P}>0,05)$, o que pode ser atribuído ao fato de que as variáveis utilizadas no cálculo da massa de ovo (produção e peso médio dos ovos) permaneceram inalteradas.
A redução no consumo, nesta pesquisa, não promoveu mudanças significativas na massa de ovo produzida; assim, a conversão alimentar foi melhor nos níveis de 15 e 20\% de farelo de coco em relação ao controle.

A qualidade dos ovos medida pelas unidades Haugh e a coloração da gema não foram influenciadas pela inclusão do farelo de coco nas rações. A redução na coloração da gema dos ovos, único problema relacionado à qualidade dos ovos de aves alimentadas com farelo de coco (Braga et al., 2005), foi contornada com a inclusão de pigmento às rações, conforme recomendações do fabricante do produto.

\section{Conclusões}

A inclusão de farelo de coco pode modificar a digestibilidade dos nutrientes e, conseqüentemente, o valor nutricional de rações para poedeiras. A inclusão de farelo de coco em rações para essas aves deve ser feita em associação a uma fonte de pigmento e não deve ultrapassar o nível de $15 \%$.

\section{Literatura Citada}

BRAGA, C.V.P.; FUENTES, M.F.F.; FREITAS, E.R. et al. Efeito da inclusão do farelo de coco em rações de poedeiras comerciais. Revista Brasileira de Zootecnia, v.34, p.76-80, 2005.

BUXADÉ, C.C. El huevo para consumo: bases productivas, Versión española. Madrid: Mundi Prensa/Adeos, 1993. 401p.

CLASSEN, H.L. Cereal grain starch and exogenous enzymes in poultry diets. Animal Feed Science Technology, v.62, p.21-27, 1996.

EMPRESA BRASILEIRA DE PESQUISA E AGROPECUÁRIA EMBRAPA. Tabela de composição química e valores energéticos de alimentos para suínos e aves. 3.ed. Concórdia: Embrapa, 1991. p.28-68. (Circular Técnica, 19).

FAO Agriculture. Disponivel em: <http://www.fao.org.br>. Acesso em: 29/4/2003.

FREITAS, A.C.; FUENTES, M.F.F.; FREITAS, E.R. et al. Efeito de níveis de proteína bruta e de energia metabolizável na dieta sobre o desempenho de codornas de postura. Revista Brasileira de Zootecnia, v.34, n.3, p.838-846, 2005.

JANSSEN, W.M.M.A.; CARRÉ, B. Influence of fiber on digestibility of poultry feeds. In: COLE, D.J.A.; HARESING, W. (Eds.). Recent developments in poultry nutrition. London: Butterworths, 1989. p.78-93.

MAHADEVAN, P.; PANDITTESEKERA, D.G.; WHITE, J.S.L. et al. The effects of tropical feedingstuffs on growth and first year egg production. Poultry Science, v.36, p.287-295, 1957.

MATEOS, G.G.; REBOLLAR, P.G.; MENDEL, P. Utilización de grasas y subproductos lipídicos em monograstricos. In: CURSO DE ESPECIALIZACIÓN FUNDACIÓN ESPAÑOLA PARA EL DESARROLLO DE LA NUTRICIÓN ANIMAL (FEDNA), 12. 1996, Madri. Apostila... Madri: FEDNA, 1996. p.3-20.

McDONALD, P.; EDWARDS, R.A.; GREENHALGH, J.F.P. Animal nutrition. 4.ed. Essex: Longman Scientific Technical, 1988. 543p.

PANIGRAHI, S. Effect of different copra meals and amino acid supplementation on broiler chick growth. British Poultry Science, v.33, p.683-687, 1992. 
PANIGRAHI, S. Effects on egg production of including high residual lipid copra meal in laying hen diets. British Poultry Science, v.30, p.305-312, 1989

PINTO, R.; FERREIRA, A.S.; ALBINO, L.F.T. et al. Níveis de proteína e energia para codornas japonesas em postura. Revista Brasileira de Zootecnia, v.31, n.4, p.1761-1770, 2002.

RODRIGUES-PALENZUELA, P.; GARCIA, J.; DE BLAS, C. Fibra soluble y su implicación en nutrición animal: enzimas y probióticos. In: CURSO DE ESPECIALIZACIÓN FUNDACIÓN ESPAÑOLA PARA EL DESARROLLO DE LA NUTRICIÓN ANIMAL (FEDNA), 14., 1998, Barcelona. Apostila... Barcelona: FEDNA, 1998. p.229-239.

ROSTAGNO, H.S.; ALBINO, L.F.T.; DONZELE, J.L. et al. Tabelas brasileiras para aves e suínos: composição de alimentos e exigências nutricionais. Viçosa, MG: Universidade Federal de Viçosa, 2000. 141p.

SAKOMURA, N.K.; SILVA, R.; LAURENTZ, A.C. et al. Avaliação da soja integral tostada ou extrusada sobre o desempenho de frangos de corte. Revista Brasileira Zootecnia, v.27, p.584594, 1998.
SAKOMURA, N.K.; LONGO, F.A.; RABELLO, C.B. et al. Efeito do nível de energia metabolizável da dieta no desempenho e metabolismo energético de frangos de corte. Revista Brasileira de Zootecnia, v.33, p.1758-1767, 2004.

SILVA, D.J.; QUEIROZ, A.C. Análise de alimentos: métodos químicos e biológicos. 3.ed. Viçosa, MG: Editora UFV, 2002. $165 p$.

SOLDEVILA, M.; ROJAS DA PORTA, M. Effect of differente levels of coconut meal on egg production. Journal of Agriculture of University of Puerto Rico, v.60, p.635-638, 1976.

STATISTICAL ANALYSIS SYSTEM - SAS. SAS/STAT: user's guide. Version 6, 12.ed. Cary: 2000. (CD-ROM).

VASCONCELOS, R.Q.; BRANDÃO, J.S. Efeito de níveis de farelo de coco na dieta inicial sobre o desempenho de frangos de corte. Revista da Sociedade Brasileira de Zootecnia, v.24, p.391400, 1995. 